\title{
Reply to: laparoscopic slit mesh repair of parastomal hernia using a designated mesh: long-term results
}

\author{
Birgitta M. E. Hansson
}

Received: 1 March 2012/ Accepted: 29 March 2012/Published online: 12 December 2012

(C) Springer Science+Business Media New York 2012

I read with interest the recently published paper of H. Mizrahi et al. on laparoscopic parastomal hernia surgery with a slit mesh technique [1]. Parastomal hernia surgery has been my principal point of interest for many years. In their discussion, the authors refer incorrectly to two of my publications $[2,3]$.

The authors note, "After having these disappointing results, the same group of authors (Hansson et al.) published a modified technique using both open and laparoscopic approaches, with a hand-made 'funnel-shaped' Gore-Tex dual mesh, but long-term results are yet to be published." Then they refer to the first publication, which was published in this journal in 2007 [2].

This assertion is simply not true. No modification of the technique was performed, and no open technique was described. Rather, as the title of the publication indicates, this is a publication of the short-term results of a prospective clinical study on 55 consecutive patients operated solely by laparoscopy [2]. It was concluded that the laparoscopic keyhole technique is a safe and feasible technique to repair parastomal hernias.
However, a follow-up article was published in this journal in 2009. It revealed the long-term results of the same study with a specific focus on the recurrence rate. It was concluded that the laparoscopic keyhole technique resulted in a high recurrence rate [3].

\section{References}

1. Mizrahi H, Bhattacharya P, Parker MC (2012) Laparoscopic slit mesh repair of parastomal hernia using a designated mesh: longterm results. Surg Endosc 26:267-270

2. Hansson BME, de Hingh IHJT, Bleichrodt RP (2007) Laparoscopic parastomal hernia repair is feasible and safe: early results of a prospective clinical study including 55 consecutive patients. Surg Endosc 21:989-993

3. Hansson BME, Bleichrodt RP, de Hingh IH (2009) Laparoscopic parastomal hernia repair using a keyhole technique results in a high recurrence rate. Surg Endosc 23:1456-1459

B. M. E. Hansson ( $₫)$

Department of Surgery, Canisius - Wilhelmina Hospital,

Nijmegen, The Netherlands

e-mail: birgittahansson@hotmail.com 